\title{
Uso de filtros de carvão ativado granular associado a microrganismos para remoção de fármacos no tratamento de água de abastecimento
}

\author{
Use of granular activated carbon filters associated with \\ microorganisms to remove pharmaceuticals in drinking water treatment
}

\begin{abstract}
Rívea Medri Borges', Alessandro Minillo², Eliana Gertrudes de Macedo Lemos ${ }^{3}$, Heloiza Ferreira Alves do Prado ${ }^{4}$, Edson Pereira Tangerino ${ }^{5}$
\end{abstract}

\begin{abstract}
RESUMO
O modo de vida das sociedades modernas originou o aporte diário, nos ambientes aquáticos, de fármacos e outras inúmeras moléculas de uso contínuo, compostos emergentes, com potencial de risco à saúde humana principalmente pela exposição em razão da inevitável contaminação dos mananciais de abastecimento de água e da transferência para as estações de tratamento de água (ETA), onde não são removidos. O uso de carvão ativado granular na filtração demonstra ser uma opção viável para ETA, porém, uma eficiência satisfatória requer regeneração periódica do material, onerando o tratamento. Contudo, observa-se que em baixas taxas de filtração a colonização natural dos filtros por microrganismos - formação de biofilme pode ser uma alternativa para aumentar o tempo de vida útil do carvão, bem como para decompor essas moléculas complexas em elementos minerais assimiláveis, reintroduzindo-os nos ciclos biogeoquímicos naturais. Este trabalho avaliou, durante 24 semanas, em condições de laboratório, o carvão ativado com biofilme como meio filtrante para remoção dos fármacos: diclofenaco de sódio, ibuprofeno, naproxeno e amoxicilina; experimentou em sistema batch o potencial dos microrganismos colonizadores de filtros em degradar os fármacos testados, assim como identificou filogeneticamente os microrganismos predominantes na biodegradação. Os resultados demonstram a remoção dos fármacos acima de $80 \%$. Constatou-se a presença das bactérias dos gêneros Bacillus, Burkholderia, Cupriavidus, Pseudomonas, Shinella, e Sphingomonas. Este estudo permite inferir a capacidade de remoção de fármacos por bactérias presentes em filtros de carvão ativado e o possível uso dessa tecnologia como alternativa de controle e remoção dessas substâncias no tratamento de água potável.
\end{abstract}

Palavras-chave: tratamento de água de abastecimento; contaminantes emergentes; remoção de fármacos; carvão ativado granular; biofilme.

\begin{abstract}
The way of life of modern societies has originated the daily intake of pharmaceuticals and numerous other molecules of continuous use in aquatic environments, emerging compounds that brings potential risk for human health mainly due to exposure resulted from the inevitable contamination of sources of drinking water supply and its transference to the water treatment plants (WTP) where they are not removed. The use of granular activated carbon in filters proves to be a viable option for WTP, but satisfactory efficiency requires periodic regeneration of the material, burdening the treatment costs. However, it is noted that under low filtration rates, the natural colonization of filters by microorganisms - biofilm formation - may be an alternative for increasing the lifetime of carbon, as well as to decompose these complex molecules into assimilable mineral elements, thereby reintroducing them to the natural biogeochemical cycles. This study evaluated the activated carbon with biofilm as the filter media, during 24 weeks, under laboratory conditions, considering the removal of the pharmaceuticals diclofenac sodium, ibuprofen, naproxen and amoxicillin; experienced under batch system the potential of the microorganisms adhering to the filters in degrade the tested drugs, as well as phylogenetically identified the predominant microorganisms in biodegradation. The results show drug removal over $80 \%$. It was observed the presence of the bacteria genus Bacillus, Burkholderia, Cupriavidus, Pseudomonas, Shinella and Sphingomonas. This study allows us to infer the capacity to remove pharmaceuticals by the bacteria present in the activated carbon filters, and the possible use of this technology as an alternative for control and removal of these substances in drinking water treatment.
\end{abstract}

Keywords: drinking water treatment; emerging contaminants; pharmaceuticals removal; granular activated carbon; biofilm.

\footnotetext{
"Mestre em Recursos Hídricos e Tecnologias Ambientais pela Universidade Estadual Paulista “Júlio de Mesquita Filho” (UNESP). Pesquisadora Visitante da Universidade Federal de Santa Catarina (UFSC) - Florianópolis (SC), Brasil.

${ }^{2}$ Pós-doutor em Recursos Hídricos e Tecnologias Ambientais pela UNESP. Pesquisador Visitante na Faculdade de Engenharia da Universidade Federal da Grande Dourados (UFGD) - Dourados (MS), Brasil.

${ }^{3}$ Pós-doutora em Microbiologia pela University of North Carolina. Professora Titular do Departamento de Tecnologia da UNESP - Jaboticabal (SP), Brasil.

${ }^{4}$ Doutora em Microbiologia Aplicada pela UNESP. Professora do Departamento de Fitotecnia, Tecnologia de Alimentos e Sócio Economia da UNESP - IIha Solteira (SP), Brasil. ${ }^{5}$ Doutor em Engenharia Hidráulica e Saneamento pela Universidade de São Paulo (USP). Professor do Departamento de Engenharia Civil da UNESP - Ilha Solteira (SP), Brasil. Endereço para correspondência: Rívea Medri Borges - Praça Santos Dumont, 94 - Trindade - 88036-680 - Florianópolis (SC), Brasil - E-mail: riveamborges@gmail.com Recebido: 18/06/13 - Aceito: 15/O3/16 - Reg. ABES: 118787
} 


\section{INTRODUÇÃO}

Nas últimas décadas, a crescente expansão dos centros urbanos, das indústrias, da agricultura e da pecuária tem contribuído com o aumento na contaminação de rios, lagos e reservatórios por diversos compostos orgânicos sintéticos, estranhos aos seres vivos, conhecidos como compostos emergentes. Atualmente são mais de 3 milhões de compostos orgânicos sintéticos, número que aumenta numa taxa de aproximadamente 5 a 10\% ao ano. Estima-se que pelo menos 100 mil desses compostos são produzidos regularmente, um equivalente a 200 milhões de toneladas por ano, dos quais 20 a $30 \%$ podem certamente chegar aos ambientes aquáticos.

Apesar de poucos estudos, tem-se comprovado que muitos dos compostos emergentes causam efeitos em nível bioquímico, com consequências sobre o sistema endócrino e, em alguns casos, podem acarretar deficiência no sistema imunológico, carcinogenia e mutagenia. Dessa forma, apesar de ser impossível avaliar a sua real magnitude, o crescente emprego desses compostos representa um risco ambiental concreto, principalmente pela incapacidade de acompanhar o comportamento, a velocidade de distribuição, os níveis e efeitos ambientais.

Dentre os compostos emergentes estão os fármacos representados por uma série de medicamentos, tais como antibióticos, analgésicos, anti-inflamatórios e contraceptivos orais (FENT; WESTON; CAMINADA, 2006). A ocorrência no ambiente natural advém principalmente pelo uso intenso e extensivo no tratamento de doenças, sendo esses excretados pelo organismo na forma não metabolizada ou como metabólitos ativos, introduzidos no meio ambiente, principalmente a partir do lançamento via efluentes municipais nos corpos receptores de águas servidas, bem como por efluentes de atividades industriais (REIS FILHO et al., 2007; CHAPMAN, 2006; PETROVIĆ et al., 2005).

Apesar das modernas tecnologias de tratamento adotadas nas estações de tratamento de esgoto (ETE), os fármacos não são completamente eliminados (GHISELLI, 2006). Nas águas naturais são lipofílicos, persistentes e, dependendo da capacidade de autodepuração do corpo receptor e da estabilidade das moléculas, podem chegar às águas das populações assentadas a jusante dos lançamentos, e se transferir para estações de tratamento de água (ETA), onde não são removidos pelos sistemas convencionais (JONES; LESTER; VOULVOULIS, 2005), estendendo-se à água de abastecimento humano, configurando um risco potencial de exposição à saúde humana (WEBB et al., 2003).

A presença de fármacos em águas aduzidas para ETA representa atualmente um desafio às companhias de saneamento. Em todo o mundo, avaliações criteriosas vêm sendo realizadas sobre os limites seguros de concentrações de fármacos na água potável, a fim de estabelecer diretrizes e regulamentações que protejam a saúde humana e os ecossistemas naturais dos indesejáveis efeitos dessas substâncias. Em 2010, o Programa das Nações Unidas pelo Meio Ambiente (PNUMA), no objetivo de resguardar o direito humano de água segura para todos, fez um apelo à comunidade mundial para que direcionem seus estudos para o desenvolvimento e aprimoramento de novas tecnologias de remoção dos compostos emergentes (CORCORAN et al., 2010).

Nesse contexto, uma tecnologia promissora é o uso de filtros de carvão ativado granular com biofilme (BUNDY et al., 2007). A principal característica desse sistema está na capacidade desses biofiltros em remover compostos biodegradáveis através da ação dos microrganismos (SERVAIS et al., 1992), além de representar uma possível otimização operacional, redução dos custos do tratamento da água em ETA e prolongamento da vida útil dos filtros. Outra consideração é a possibilidade de reduzir as chances de transpasse de contaminantes do filtro para a água efluente, mantendo assim a produção de água potável com padrão de eficiência (SIMPSON, 2008). Considerando esses aspectos, o presente estudo avaliou o carvão ativado granular na presença de atividade biológica como meio filtrante para a remoção dos fármacos: diclofenaco de sódio, ibuprofeno, naproxeno e amoxicilina, em condições de laboratório, assim como a biodegradação dos compostos pelos microrganismos aderidos aos filtros e identificou filogeneticamente a comunidade microbiana participante no processo de degradação dos fármacos testados.

\section{METODOLOGIA}

O estudo foi realizado em três etapas distintas:

1. teste de biodegradação dos fármacos por microrganismos em sistemas batch;

2. experimento de remoção dos compostos farmacológicos em filtros de carvão ativados em bancada de laboratório; e

3. identificação filogenética dos microrganismos associados aos filtros biológicos de carvão.

Em todas as etapas do experimento utilizou-se água natural coletada no reservatório localizado no Bairro Ipê, no município de Ilha Solteira, São Paulo. A área de captação da microbacia da Lagoa do Ipê apresenta aproximadamente 286 ha, de uso urbano-rural, com grande presença de pastagem e cultivos agrícolas anuais e perenes. Segundo Basso e Carvalho (2007), o Índice de Qualidade de Água (IQA), da Lagoa do Ipê apresenta média igual a 58, qualidade considerada boa pela Escala de IQA (CETESB, 2004). Estudos de caracterização para abastecimento público, realizados por Tavares (2008), mostraram que a água da Lagoa do Ipê se enquadra nos limites estabelecidos por Di Bernardo, Brandão e Heller (1999) para filtração lenta desde que seja submetida a um pré-tratamento. 


\section{Ensaio 1: teste de biodegradação dos fármacos}

O experimento de biodegradação foi realizado durante 180 dias, em sistema batch com objetivo de testar a capacidade do biofilme proveniente de filtros biológicos de carvão da Instalação Piloto de Filtração em Múltiplas Etapas do Departamento de Engenharia Civil (DEC) da Faculdade de Engenharia de Ilha Solteira da Universidade Estadual Paulista "Júlio de Mesquita Filho" (FEIS-UNESP). A água de estudo foi filtrada em filtro de celulose $(1,0 \mu \mathrm{m})$, esterilizada $\left(120^{\circ} \mathrm{C}\right.$ por $\left.15 \mathrm{~min}\right)$ e posteriormente recebeu o grupo de anti-inflamatórios composto por ibuprofeno, naproxeno e diclofenaco de sódio, todos na concentração de $20 \mu \mathrm{g} . \mathrm{L}^{-1}$, quantidade para permitir mensurar as alterações ao longo de 6 meses de experimento e que, segundo os trabalhos de Ghiselli (2006), Daughton (2001) e Zwiener e Frimmel (2000), reproduz as concentrações que podem ser encontradas em águas superficiais. Os fármacos utilizados nos ensaios foram obtidos da Sigma-Aldrich, os quais demonstraram ter 97 a $98 \%$ de grau de pureza.

A água de estudo então foi acondicionada em galão de vidro (4 L), âmbar, esterilizado. Ao galão foram inoculados $10 \%$ (v/v) de uma solução aquosa, filtrada $(1,0 \mu \mathrm{m})$ contendo o biofilme. Para o controle foi usado um galão sob as mesmas condições descritas anteriormente, sem o acréscimo do inóculo com microrganismos, e ainda recebendo azida de sódio (4 mg.L $\left.\mathrm{L}^{-1}\right)$ à água de estudo, a fim de inibir qualquer atividade metabólica de microrganismos. Os galões foram mantidos no escuro, em sistema fechado, sob agitação orbital (100 rpm) e temperatura aproximada de $23 \pm 2^{\circ} \mathrm{C}$. A cada semana foram recolhidas amostras $(100 \mathrm{~mL})$ para leituras do pH (Digimed DM 20) e quantificação das concentrações dos fármacos por cromatografia (HPLC - Prominence, Shimadzu).

\section{Ensaio 2: filtração biológica dos fármacos}

Para esse ensaio, a água de estudo foi filtrada em filtro de celulose $(1,0 \mu \mathrm{m})$ e esterilizada $\left(120^{\circ} \mathrm{C}\right.$ por $\left.15 \mathrm{~min}\right)$, recebendo posteriormente a adição dos compostos farmacológicos: os anti-inflamatórios diclofenaco, ibuprofeno, naproxeno e um antibiótico, a amoxicilina, cujas características estão apresentadas na Tabela 1. Todos os fármacos na concentração de 1,0 $\mu$ g. $\mathrm{L}^{-1}$, que segundo os trabalhos de Ghiselli (2006), Daughton (2001) e Zwiener e Frimmel (2000) reproduz as concentrações que podem ser encontradas nas águas saídas das estações de tratamento.

O carvão ativado granular utilizado nos filtros foi escolhido com base em ensaios prévios realizados em projetos de pesquisa do Laboratório de Saneamento da FEIS-UNESP. O carvão selecionado foi de casca de coco, com grânulos de 0,35 a 0,50 mm. Esse carvão, após ensaios sobre o potencial de adsorção realizados nos estudos anteriores do Laboratório de Saneamento, apresentou isoterma do tipo II, segundo a classificação Brunauer-Emmer-Teller (BET) descrita por Brunauer, Emmett e Teller (1938). A isoterma do tipo II, segundo proposto por Gilles et al. (1960), se assemelha à isoterma H4, se caracteriza pela alta afinidade com o soluto adsorvido, onde a adsorção aumenta com o aumento da concentração do soluto na fase líquida até atingir um platô, em que o soluto não mais responde ao aumento da concentração e a adsorção é interrompida.

Para os ensaios de bancada foram utilizados 8 filtros de carvão ativado confeccionados em colunas de vidro (borosilicato) de $10 \mathrm{~cm}$, com diâmetro interno de $1,2 \mathrm{~cm}$, preenchidos por $3 \mathrm{~cm}$ de uma camada do carvão ativado, aproximadamente 3,5 gramas (peso úmido).

Tabela 1 - Características dos compostos farmacológicos em estudo.

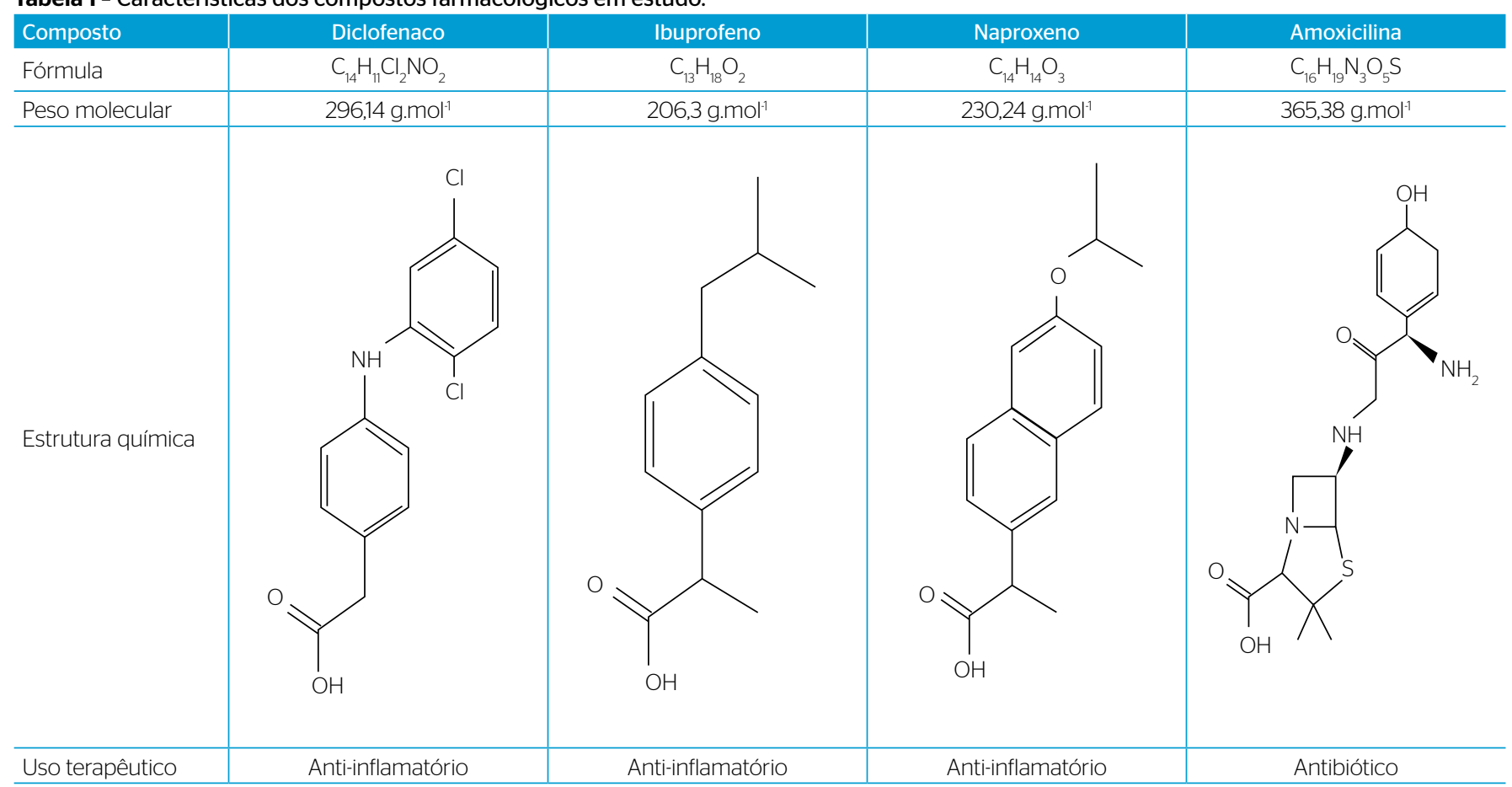


Quatro desses filtros, denominados como CAB, foram destinados para filtração com atividade biológica recebendo inóculo de biofilme proveniente do leito filtrante de uma coluna de polimento contendo carvão ativado da Instalação Piloto de Filtração em Múltiplas Etapas do Departamento de Engenharia Civil (DEC) da FEIS-UNESP. Os outros quatro filtros foram utilizados para o controle, denominados CAG, sem inoculação de biofilme. As duas configurações de filtros receberam continuamente água natural provinda do reservatório Ipê durante dois meses. Para inibição de qualquer atividade metabólica de microrganismos nos filtros CAG, foi previamente adicionado azida de sódio ( $\left.4 \mathrm{mg} . \mathrm{L}^{-1}\right)$ à água de exposição. A atividade biológica dos filtros $\mathrm{CAB}$ foi indicada pela taxa de consumo do oxigênio, em comparação com o controle.

Após esse período de maturação, as duas configurações de filtros ( $\mathrm{CAB}$ e $\mathrm{CAG}$ ) foram expostas à água de estudo em fluxo contínuo por uma bomba peristáltica multicanais (Ismatec RS 232 IN), conforme representado na Figura 1. Os filtros foram operados sob fluxo descente com taxa de filtração constante e igual a $3,6 \mathrm{~m}^{3} \cdot \mathrm{m}^{-2} \cdot \mathrm{d}^{-1}$, vazão de $3 \mathrm{~mL} \cdot \mathrm{min}^{-1}$ e tempo de contato de $12 \mathrm{~min}$. O experimento foi realizado durante 180 dias, sendo recolhidas amostras $(200 \mathrm{~mL})$ afluente e efluente dos filtros semanalmente, para leituras do $\mathrm{pH}$ (DIGIMED DM 20); determinação das concentrações dos fármacos (HPLC Prominence, Shimadzu); e níveis de carbono orgânico dissolvido (TOC 5000-A, Shimadzu).

\section{Preparo das amostras e análise em sistema cromatográfico}

Para análise da concentração dos fármacos foi empregada a técnica de extração em fase sólida (SPE) com cartuchos preenchidos com sílica tipo C18, conforme metodologia adaptada de Nebot, Gibb e Boyd (2007). A determinação dos fármacos foi realizada em um cromatógrafo líquido de alta eficiência (Shimadzu), equipado com detector Photodiode Array (SPD-M20A), duas bombas de alta pressão (LC-20AT e LC 20AD), em coluna de fase reversa C-18 (modelo Shim-pack), com 4,6 x 250 mm e diâmetro de partícula de $5 \mu \mathrm{m}$, segundo Nebot, Gibb e Boyd (2007), com adaptações. A fase móvel foi constituída por metanol e água acidificada com $0,1 \%$ (v/v) de ácido trifluoracético (TFA), sendo utilizado um fluxo de $1 \mathrm{~mL} \cdot \mathrm{min}^{-1}$ e um tempo de corrida de 18 min para cada amostra analisada, em triplicata.

A quantificação de cada fármaco foi efetuada de acordo com os seus respectivos tempos de retenção (TR) e também através de cada perfil espectrofotométrico, nos comprimentos de onda específicos de detecção para cada composto. As curvas analíticas foram efetuadas através do método do padrão interno, concomitantemente, os limites de detecção (LD) e os limites de quantificação (LQ) (g.mL ${ }^{-1}$ ) também foram obtidos por meio de planilha de validação proposta por Ribeiro e Ferreira (2008). A seguir está apresentado o perfil cromatográfico (Figura 2) dos padrões utilizados como base de reconhecimento para os fármacos estudados nas amostras recolhidas afluentes e efluentes dos filtros de carvão colonizados (CAB) e não colonizados por microrganismos (CAG).

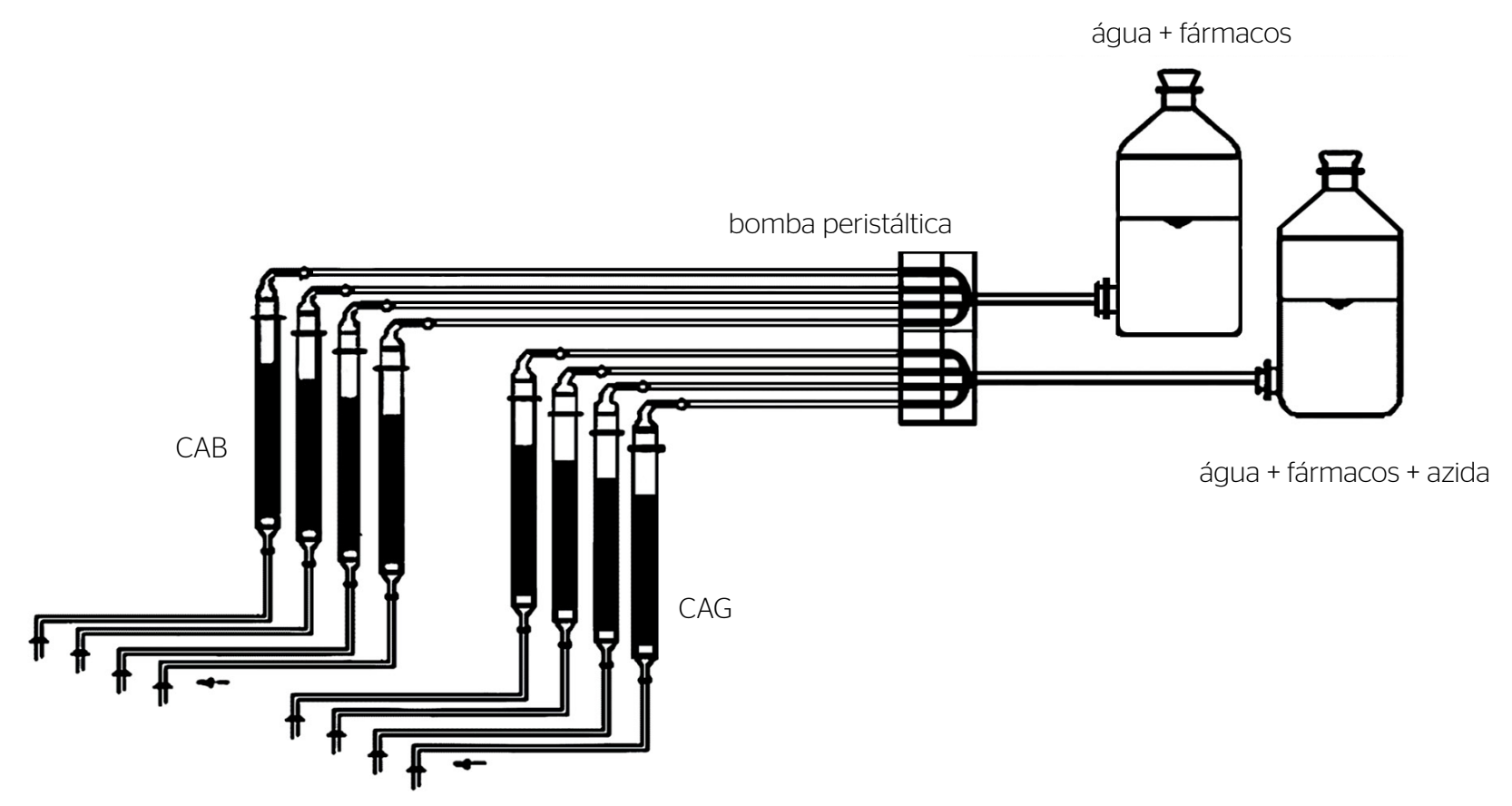

CAB: filtro com atividade biológica; CAG: filtro sem inoculação de biofilme.

Figura 1 - Configuração do sistema experimental com filtros de carvão colonizados e não colonizados por microrganismos. 


\section{Ensaio 3 - isolamento e caracterização fenotípica dos microrganismos nos filtros colonizados por microrganismos}

Os microrganismos presentes nos filtros $\mathrm{CAB}$ foram submetidos ao processo de isolamento e caracterização filogenética, por meio da retirada de um volume ( $1 \mathrm{~mL}$ ) de amostra na superfície e no interior dos filtros CAB. O material recolhido foi homogeneizado, sendo realizadas diluições decimais de uma alíquota $(1 \mathrm{~mL})$ em solução de Ringer para o posterior plaqueamento em meios sólidos contendo meio de cultura ágar padrão para contagem (PCA). As placas foram incubadas a $25^{\circ} \mathrm{C}$, no escuro, por uma semana.

Após incubação, foram observadas as principais características das colônias obtidas. O isolado de cada colônia foi obtido por meio de sucessivos plaqueamentos por esgotamento em estrias e então transferido para tubos de ensaio contendo o meio de cultivo inclinado e mantido em refrigeração a $25^{\circ} \mathrm{C}$. Para cada colônia isolada foram observadas características morfológicas (coloração, tamanho e tipo de borda das colônias), coloração diferencial de Gram, e verificação da formação de esporos (TORTORA; FUNKE; CASE, 2003), de modo a obter informações dos possíveis grupos microbianos presentes nos filtros. Em seguida foi realizada a produção massiva de cada isolado para extração do DNA e identificação filogenética.

Os microrganismos isolados foram cultivados em tubos Falcon com o meio de cultura durante 24 horas. Os cultivados foram centrifugados a $5.000 \mathrm{rpm}$ durante 9 minutos, sendo os precipitados
( $5 \mathrm{~mL}$ ) encaminhados para a extração do DNA ao Laboratório de Bioquímica de Microrganismos e Plantas da UNESP de Jaboticabal. A extração do DNA dos isolados foi realizada utilizando o kit FastDNA SPIN Kit for Soil (BIO 101, Quantum Biotechnologies), seguindo as instruções do fabricante. O gene $16 \mathrm{~S}$ rRNA do material genético extraído de cada amostra foi amplificado pela técnica de reação em cadeia da polimersase (PCR). Os amplicons gerados foram confirmados por eletroforese em gel de agarose e visualizados em um fotodocumentador (Gel Doc 1000).

Os produtos da PCR do gene 16S rRNA foram sequenciados em um sequenciador de capilar modelo ABI 3700 (Applied Biosystems, Foster City, CA, USA). As sequências foram analisadas com o auxílio do programa Sequencing Analysis 3.4 e pelo programa Phred/Phrap (EWING et al., 1998; EWING \& GREEN, 1998) e comparadas com os bancos de dados de genes ribossomais: Ribosomal Database Project II - RDP II (MAIDAK, 2010), através do programa Classifier, e National Center for Biotechnology Information - NCBI (SAYERS, 2010), por meio do programa Blast. Todas as sequências do gene $16 \mathrm{~S}$ rRNA obtidas neste estudo foram cadastradas no Banco Internacional de Genes (GenBank).

\section{RESULTADOS E DISCUSSÃO}

Os dados obtidos durante o estudo foram armazenados em planilhas eletrônicas e submetidos a análises estatísticas com o teste de Tukey $(\mathrm{p}<0,05)$ através do software estatístico SPSS 11.5 for Windows, de

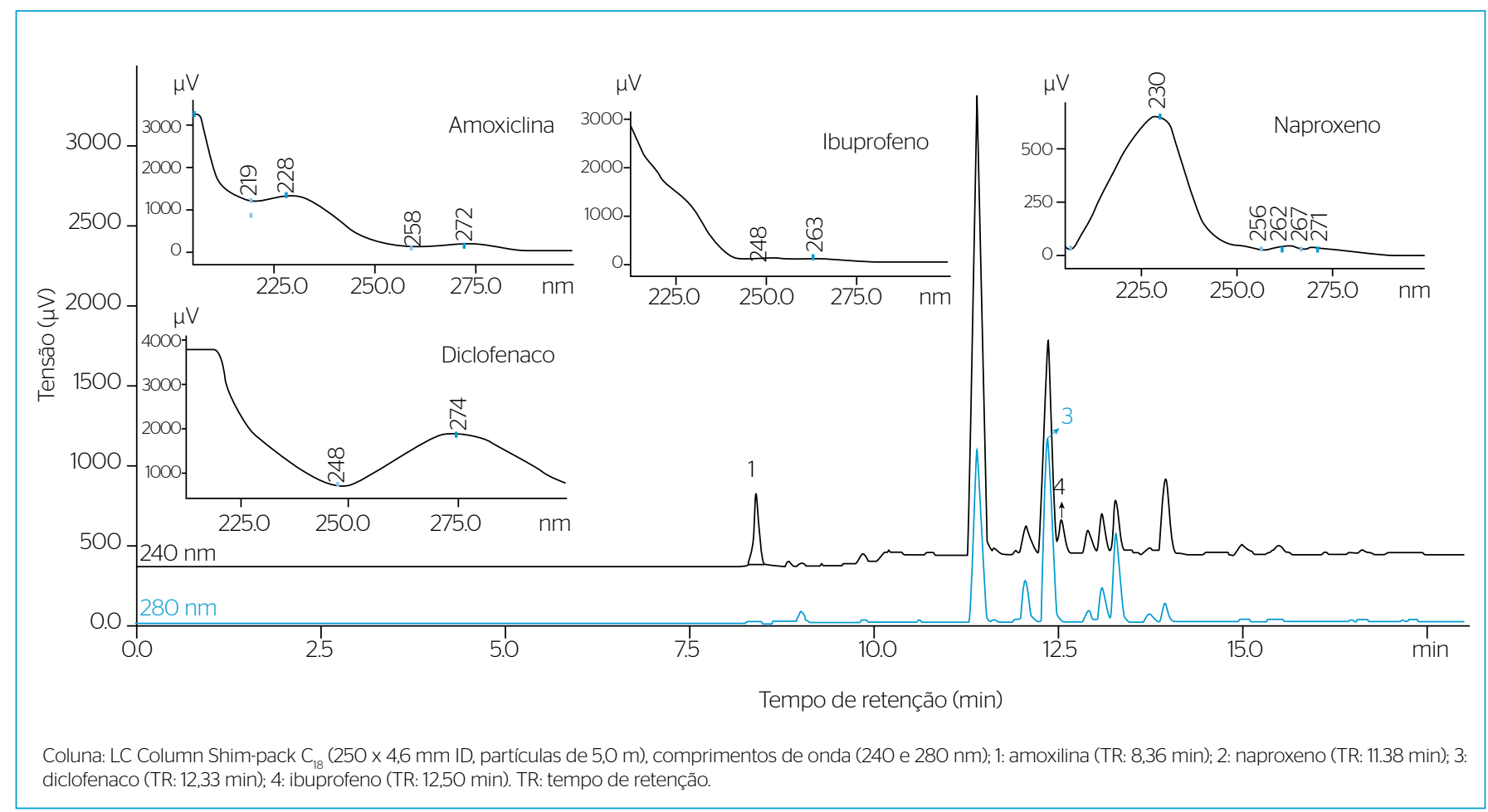

Figura 2 - Perfil cromatográfico de padrões de fármacos. 
modo a avaliar o desempenho dos filtros, bem como o comportamento desses frente a outros parâmetros físicos e químicos da água de estudo.

\section{Ensaio de biodegradação dos fármacos}

Esse ensaio evidenciou expressiva degradação dos compostos farmacológicos por microrganismos (Figura 3). De modo geral, verificou-se que a biodegradação atingiu valores próximos a $90 \%$ para diclofenaco (Figura 3B) e naproxeno (Figura 3C), e 99\% para o ibuprofeno (Figura 3A). Em concordância com outros trabalhos envolvendo o uso de bactérias como uma via de degradação de fármacos em ensaios de laboratório (CHUA; YAP; NG, 1996), o presente estudo demonstra o potencial de metabolização desses compostos por microrganismos (bactérias) colonizadores de filtros biológicos de carvão. Os estudos sobre o potencial de degradação das bactérias sugerem que ao longo do tempo o declínio da matéria orgânica usualmente utilizada pelos microrganismos como elementos nutricionais induz o uso dos fármacos como fonte de carbono e energia, propiciando a degradação. Uma situação semelhante foi observada por Park et al. (2001) no trabalho de degradação de microcistina, que verificou tempo de degradação do contaminante quatro vezes superior em água com ausência de nutrientes orgânicos.
As substâncias avaliadas neste estudo representam importantes grupos de drogas com diferentes estruturas químicas e modos de ação terapêutica. A oxidação natural da molécula foi verificada apenas para o composto ibuprofeno, evidenciando a estabilidade dessas moléculas no meio aquático e sua difícil degradabilidade. A partir da comparação entre os dois tratamentos infere-se que a metabolização dos compostos farmacológicos pelas bactérias iniciou a partir da $5^{\mathrm{a}}$ semana, ou seja, após 35 dias. A necessidade de dias de contato entre composto-microrganismo para iniciar a biodegradação, segundo estudos sobre biofilme para o uso em tratamento de água, pode ser propiciada ao associar os microrganismos ao carvão. De acordo com a literatura, nessa associação o contaminante (adsorvato) é adsorvido primeiramente pelo carvão e posteriormente as bactérias captam o contaminante nos sítios adsortivos do carvão e os utilizam como fonte nutricional promovendo sua degradação (SERVAIS et al., 1992; SEREDYNSKA-SOBECKA et al., 2006).

\section{Filtração biológica dos fármacos}

Os resultados (Figura 4) exibiram a remoção dos quatro fármacos nos filtros biológicos durante o período avaliado, com valores ligeiramente maiores aos registrados na filtração apenas com carvão. Embora os

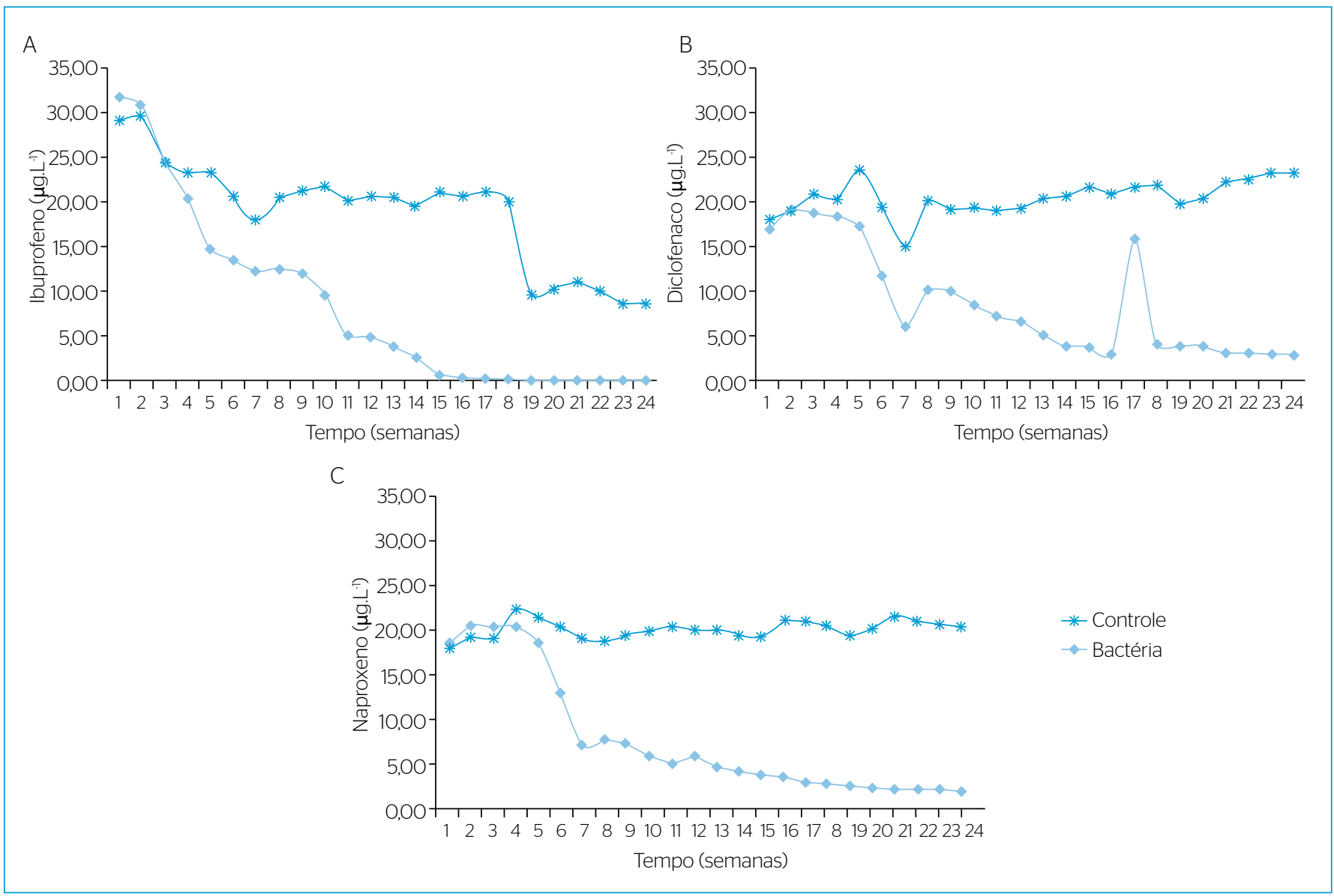

Figura 3 - Concentrações dos compostos farmacológicos quantificados entre os tratamentos testados durante o ensaio. 
filtros com microrganismos tenham apresentado um maior percentual de remoção (> 80\%) para todos os fármacos em relação aos filtros não colonizados $(<80 \%)$, não foi verificada entre os filtros uma diferença estatística significativa $(\mathrm{p}<0,05)$ na remoção dos fármacos. As duas configurações apresentaram o padrão de elevada remoção dos compostos farmacológicos, demonstrando que o carvão ativado granular utilizado, assim como as condições experimentais, foram favoráveis para a elevada capacidade de adsorção das substâncias farmacêuticas durante o experimento.

A baixa dispersão relativa nos percentuais de remoção dos quatro compostos testados durante o ensaio nos filtros $\mathrm{CAB}(\mathrm{CV} \leq 15)$, com residuais no efluente dos filtros em média menores do que $0,5 \mu \mathrm{g} . \mathrm{L}^{-1}$ sugere que a combinação dos processos de adsorção e biodegradação minimizam a flutuação da concentração dos contaminantes na água afluente, conforme relatou o trabalho de Aktas e Çeçen (2007).

Nos filtros CAG, a maior dispersão temporal na eficiência de remoção dos fármacos não pode ser justificada com os dados observados nesse experimento. O estudos de BRADY (1997) indicam que as oscilações na adsorção em carvão podem acontecer devido às concentrações do adsorvato. Na reação reversível de adsorção, as moléculas do adsorvato acumulam-se do meio de maior concentração (água) para a superfície de menor concentração (carvão); com a queda na concentração do adsorvato no afluente, a taxa da reação de adsorção diminui, gerando menor adsorção dos fármacos. Se caso por certo tempo a concentração dos fármacos no afluente for menor do que a concentração no carvão, poderá ocorrer a reação reversa (dessorção). Todavia, não foi possível comprovar a ocorrência desses efeitos no presente estudo.

A literatura tem demonstrado que a vida útil do CAG em ETA, dependendo das características da água bruta e do adsorvato, está em torno de 6 a 12 meses (SIMPSON, 2008). A redução da vida útil do carvão no leito filtrante pode ser observada pela perda significativa na eficiência de adsorção e pelo transpasse de concentrações consideráveis das moléculas adsorvidas para a água (HO, 2004; WANG et al., 2007). No presente estudo nenhuma dessas ocorrências foram observadas durante os seis meses de ensaios realizados.
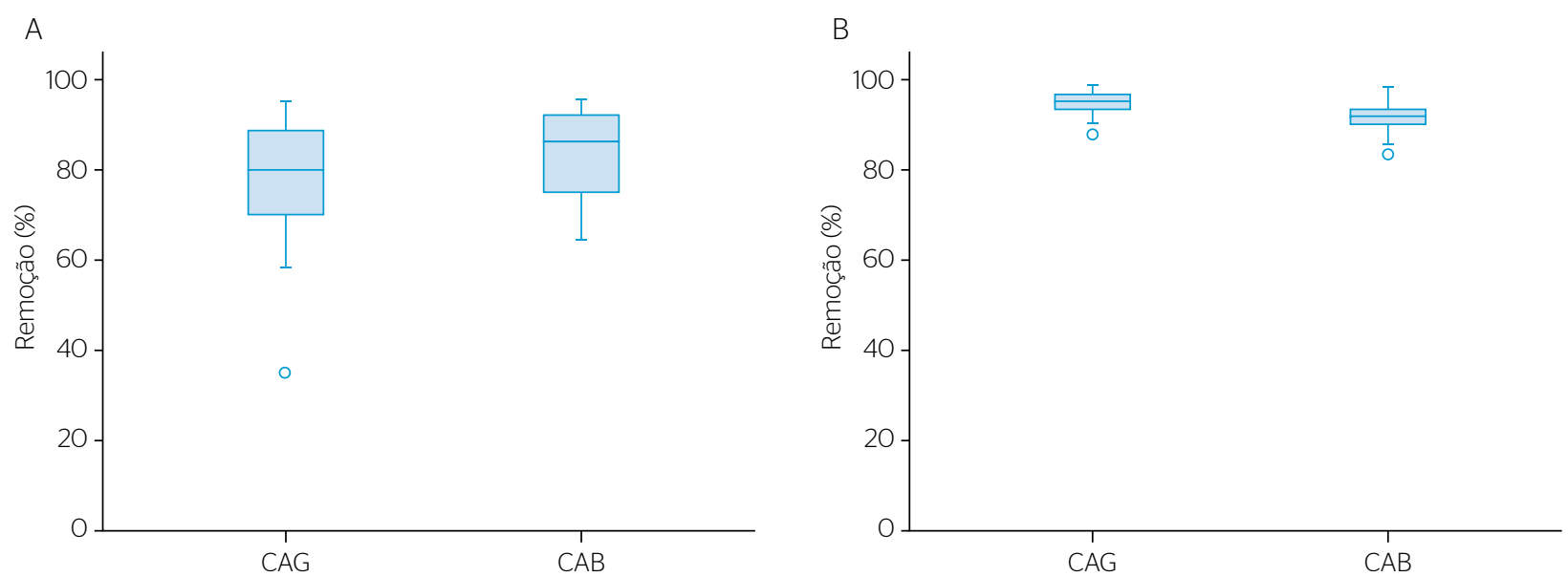

C

D
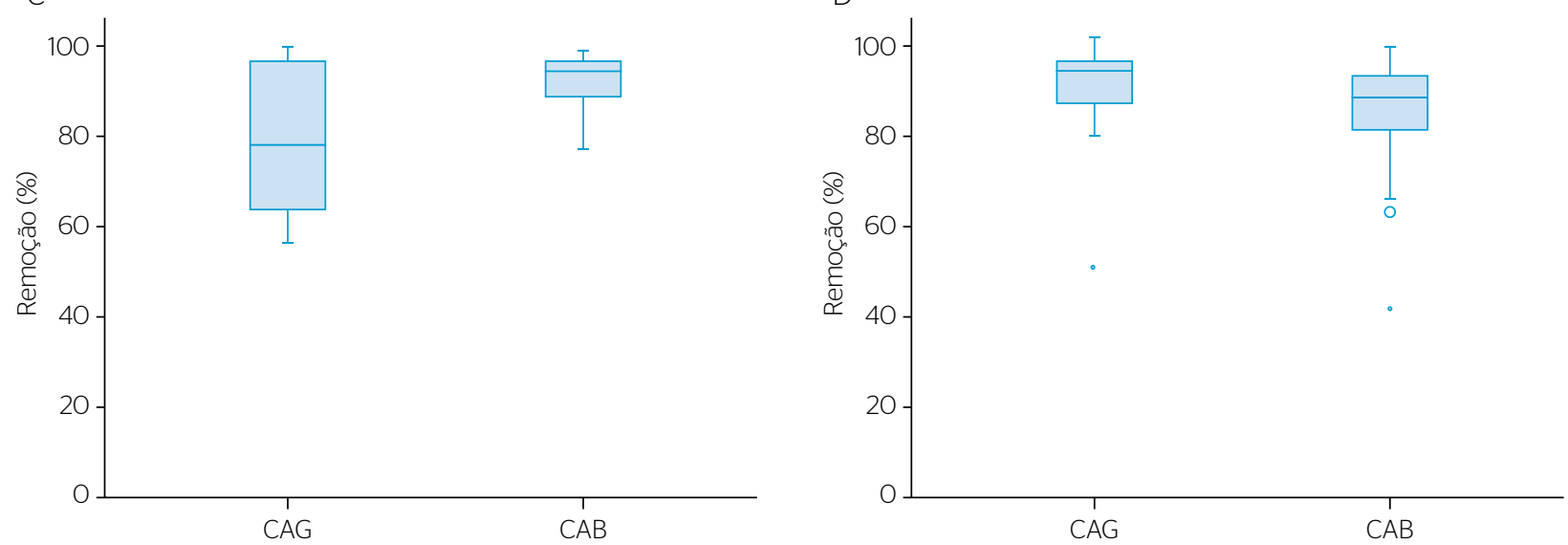

CAG: filtro sem inoculação de biofilme; CAB: filtro com atividade biológica.

Figura 4 - Distribuição dos valores de remoção nos filtros CAG e CAB. (A) amoxilina; (B) naproxeno; (C) diclofenaco; (D) ibuprofeno. 


\section{Caracterização do biofilme dos filtros de carvão biologicamente ativado}

A partir do material dos filtros $\mathrm{CAB}$ isolado e cultivado segundo os métodos microbiológicos tradicionais, foram obtidas 31 amostras de microrganismos (Tabela 2), sendo essas representadas em sua totalidade por colônias bacterianas integrantes dos filos Firmicutes (19) e Proteobacteria (12). Por meio das sequências do gene 16S rRNA amplificadas a partir do DNA das amostras isoladas, foi identificado um total de seis gêneros distintos: Bacillus, Burkholderia, Cupriavidus, Pseudomonas, Shinella e Sphingomonas.

A análise da diversidade biológica dos microrganismos constatou a dominância de bactérias do gênero Bacillus. Esse gênero é composto por microrganismos considerados ubíquos, podendo ser isolados do solo, da água doce e salgada e de alimentos. Algumas espécies do gênero Bacillus aderem fortemente a diversas superfícies sólidas por meio de estruturas não totalmente conhecidas. Sabe-se que em Bacillus cereus a presença de filamentos semelhantes ao pili (apêndice filiforme encontrado na superfície de algumas bactérias) facilita sua fixação. A elevada capacidade de fixação promove a adesão das bactérias à camada filtrante beneficiando a formação do biofilme (HUSMARK \& RÖNNER, 1990).

A prevalência do gênero Bacillus corresponde a sua resistência a amoxicilina e sua elevada capacidade de sintetizá-lo e utilizá-lo como fonte de carbono e nitrogênio descrita por Blau, Menegon e ChinChung (2006). A amoxicilina é um antibiótico $\beta$-lactâmico, que atua destruindo a parede das células bacterianas, pois se une a uma grande variedade de proteínas responsáveis pela produção de enzimas que sintetizam os alimentos, deixando-as sem ação. O gênero Bacillus possui várias espécies produtoras da enzima $\beta$-lactamase, responsáveis pela resistência a antibióticos $\beta$-lactâmicos. Essa enzima quebra o anel de quatro átomos conhecido como $\beta$-lactama (Figura 5), desativando as propriedades antibacterianas da molécula.

A presença do gênero Pseudomonas demonstra a versatilidade desse gênero em metabolizar diferentes compostos orgânicos, em razão de sua ampla capacidade de utilizar uma variedade de substratos como fonte de carbono, além da excepcional habilidade de colonizar nichos ecológicos diversos, nos quais a oferta de nutrientes é limitada, e sobreviver por longos períodos em ambientes úmidos variados (SMITH; DEZENY; DOUGLAS, 1990; KHAN; HAMAYUN; AHMED, 2006). Estudo realizados por Minillo et al. (2009) apontaram a capacidade de biodegradação de compostos farmacológicos detectada em microrganismos formadores de biofilme em filtros biológicos de carvão. Segundo os autores, bactérias gram-negativas representadas principalmente pelo gênero Pseudomonas promoveram a depleção de três compostos farmacológicos: cefalexina, diclofenaco de sódio e paracetamol.

Sobre a ocorrência dos gêneros Burkholderia, Shinella e Sphingomonas nas amostras, estudos realizados por Murdoch e Hay (2005) revelaram participação direta desses grupos no consumo de fármacos. Os autores indicaram que há estratégias metabólicas realizadas pelas Sphingomonas na degradação de ibuprofeno, propondo que a sequência de reações ocorre conforme a Figura 6. O gênero Sphingomonas também vem sendo descrito em trabalhos de filtração biológica em carvão e areia, onde isolados específicos de Sphingomonas foram inoculados no sistema filtrante com objetivo de remover microcistinas da água potável (BOURNE et al., 2006; WANG et al., 2007).

A observação que o gênero Burkholderia participa de processos de biodegradação de compostos farmacêuticos está em consonância com os estudos apresentados por Dantas et al. (2008), no qual o gênero Burkholderia destaca-se como um dos microrganismos do ambiente natural capazes de consumir antibióticos. Lemes et al. (2008) reportam

Tabela 2 - Caracterização dos isolados obtidos dos filtros biológicos de carvão segundo grau de similaridade.

\begin{tabular}{|c|c|c|c|c|c|}
\hline Isolado & Organismo & $\%$ similar & Isolado & Organismo & $\%$ similar \\
\hline R1 & Bacillus anthracis & 97 & R17 & Bacillus sp & 88 \\
\hline R2 & Bacillus methylotrophicus & 93 & $\mathrm{R} 18$ & Bacillus subtilis & 93 \\
\hline R3 & Bacillus pumilus & 91 & R19 & Bacillus thuringiensis & 99 \\
\hline R4 & Bacillus sp & 94 & $\mathrm{R} 2 \mathrm{O}$ & Burkholderia fungorum & 90 \\
\hline R5 & Bacillus sp & 89 & R21 & Burkholderia sp & 90 \\
\hline R6 & Bacillus sp & 94 & R22 & Burkholderia sp & 86 \\
\hline R7 & Bacillus sp & 97 & $\mathrm{R} 23$ & Cupriavidus sp & 86 \\
\hline R8 & Bacillus sp & 93 & R24 & Pseudomonadaceae & 89 \\
\hline R9 & Bacillus sp & 93 & R25 & Pseudomonas panipatensis & 89 \\
\hline $\mathrm{R} 10$ & Bacillus sp & 92 & R26 & Pseudomonas sp & 92 \\
\hline R11 & Bacillus sp & 88 & R27 & Pseudomonas sp & 89 \\
\hline $\mathrm{R} 12$ & Bacillus sp & 93 & R28 & Pseudomonas sp & 92 \\
\hline $\mathrm{R} 13$ & Bacillus sp & 92 & R29 & Shinella yambaruensis & 83 \\
\hline $\mathrm{R} 14$ & Bacillus sp & 93 & $\mathrm{R} 30$ & Sphingomonas sp & 84 \\
\hline $\mathrm{R} 15$ & Bacillus sp & 93 & R31 & Sphingomonas sp & 86 \\
\hline $\mathrm{R} 16$ & Bacillus sp & 98 & & & \\
\hline
\end{tabular}

Fonte: National Center for Biotechnology Information (SAYERS, 2010) e Ribosomal Database Project II (MAIDAK, 2010). 
sobre a ampla capacidade do gênero Burkholderia em degradar eficientemente cianotoxinas, demonstrando seu potencial também em colonizar e sobreviver em filtros biológicos. Quanto à presença dos gêneros Cupriavidus e Shinella na degradação de micropoluentes, também foi relatada por Iwaki e Hasegawa (2007) e Bai et al. (2009). O gênero Cupriavidus, classificado na família Burkholderiaceae, apesar de nenhum relato sobre degradação de fármacos, possivelmente contém as mesmas características genéticas das espécies Burkholderia sp, que proporciona a capacidade de consumir os compostos analisados.

$\mathrm{Na}$ busca por elucidar a degradação microbiológica dos fármacos nos tratamentos avaliados, deve-se destacar a atividade sinérgica entre os microrganismos para formar o biofilme e metabolizar os compostos. Os estudos sobre biofilme de Pereira (2001) mostrou que o desenvolvimento ocorre quando inicia o aporte de microrganismos em filme condicionador, uma camada de substâncias orgânicas adsorvidas a uma superfície sólida em contato com um meio aquoso. Com o tempo, observa-se a adesão firme de diferentes colônias de microrganismos que na sequência aumentam devido ao consumo dos nutrientes e à consequente reprodução dos microrganismos e seus polímeros extracelulares (muco). A massa microbiana formada é estratificada devido à difusão de nutrientes e oxigênio para seu interior, aumentando a diversidade biológica. Os diferentes tipos de microrganismos trocam subprodutos entre si, e por vezes uma colônia alimenta-se do subproduto da outra. É observada cooperação entre as diferentes colônias ao aderir o substrato, ao sintetizar os nutrientes e ao proteger-se de patógenos.

O isolamento e o cultivo de microrganismos é o método tradicional para caracterização microbiana, mas somente uma pequena parcela variando de 0,1 a 1,0\% de bactérias são cultiváveis utilizando os métodos padrões de cultivo (TORSVIK\& ØVREÅS, 2002; PAIXÃO, 2009). Dessa forma, é possível que linhagens de bactérias eventualmente não tenham desenvolvido nas placas de cultivo, mas podem ter atuado no consumo dos fármacos de forma direta. Esse estudo indica como positiva a realização de varreduras da diversidade microbiana presente nos biofilmes, o que auxiliaria na verificação da riqueza bacteriana envolvida na metabolização dos compostos emergentes e no conhecimento sobre a capacidade de colonizar filtros biológicos.

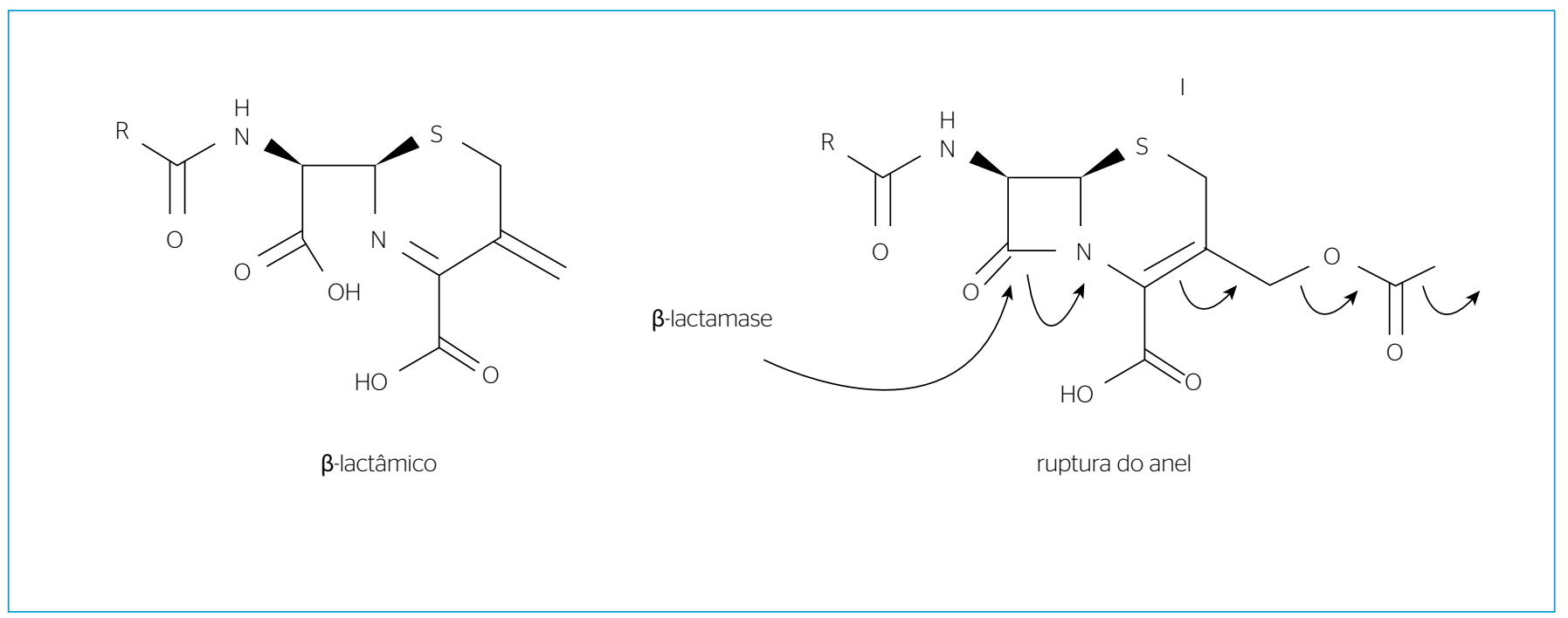

Figura 5 - Atuação da enzima $\beta$-lactamase no anel $\beta$-lactâmico.

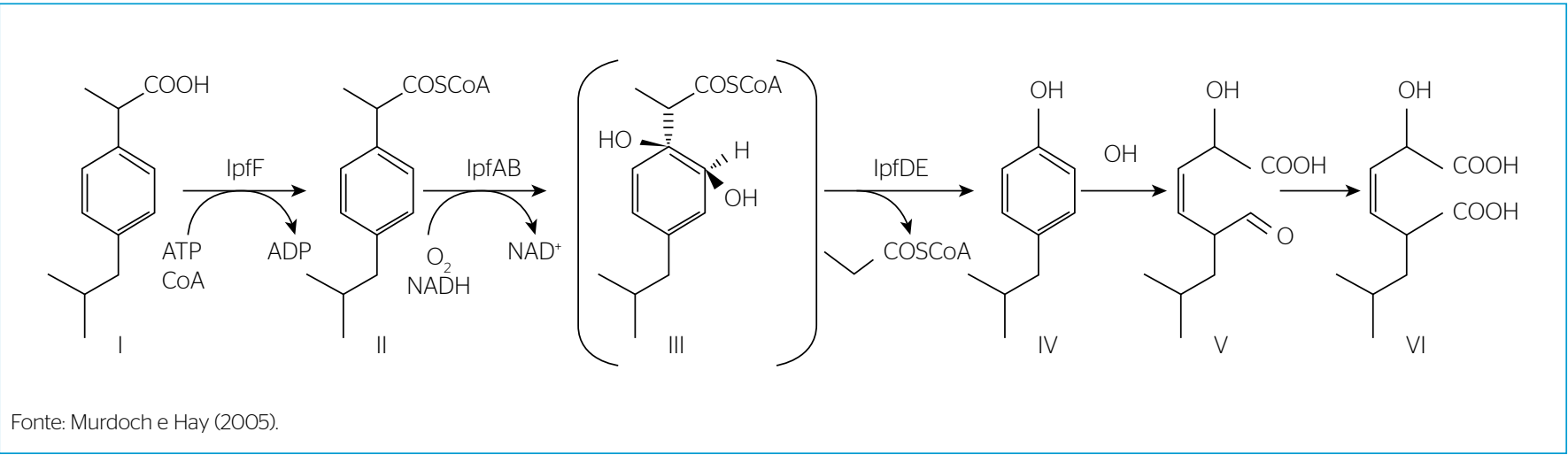

Figura 6 - Possível rota de degradação de ibuprofeno por Sphingomonas sp. 
Os resultados dos ensaios e a literatura estudada permitem inferir que os microrganismos detectados participam de reações de degradação dos compostos estudados, e foi possível comprovar os microrganismos como agentes de degradação de fármacos, demonstrando que o uso das técnicas de biodegradação pode ser um método explorado no controle e remoção para ambientes contaminados. As bactérias estão entre os organismos que melhor interagem na dinâmica de biodegradação, muitas vezes assumindo o papel central do fenômeno, em razão da sua capacidade de metabolizar uma diversidade de poluentes, enquanto que outros organismos (e.g., fungos e protozoários) podem favorecer ou mesmo afetar essa dinâmica (WATANABE, 2001).

Segundo López et al. (2005), a remoção de um determinando composto emergente (e.g., fármacos) deve oferecer uma boa alternativa na relação custo-eficácia entre os métodos não biológicos utilizados para o tratamento de águas e solos contaminados. A possibilidade de isolar microrganismos específicos ou consórcios microbianos adaptados em remover poluentes a partir de águas residuais ou água potável mostrou ser uma possível medida para degradação dessas substâncias, mas ainda não permite inferir sobre as contribuições no aumento da qualidade nos tratamentos de água. Todavia, este estudo aponta como positivo o investimento em pesquisas e sistemas pilotos operados em baixas taxas de aplicação superficial envolvendo métodos biológicos combinados a processos convencionais de potabilização, empregando-os após etapas que removam a maior carga de matéria orgânica presente nas águas naturais. $\mathrm{E}$ indica o potencial da adsorção em filtros de carvão ativado como técnica para compor novas tecnologias de remoção de compostos emergentes no objetivo de resguardar o direito humano de água segura para todos.

\section{CONCLUSÕES}

Sobre as condições empregadas no presente estudo, foi constatada a elevada capacidade de remoção dos compostos farmacológicos em ambas configurações de filtros testados. A filtração em carvão ativado, nas condições empregadas neste estudo, demonstrou ser viável para adsorção e remoção de fármacos.

O carvão ativado mostrou seu potencial como suporte para o desenvolvimento de microrganismos (biofilme) capazes de metabolizar os compostos farmacológicos testados, sua superfície porosa é acessível para fixação e colonização microbiológica. As bactérias foram predominantes no biofilme formado no filtro durante o experimento, indicando seu potencial para compor processos de biofiltração em ETA.

Foram registrados seis gêneros distintos de bactérias presentes no biofilme: Bacillus, Burkholderia, Cupriavidus, Pseudomonas, Shinella, e Sphingomonas, com destaque ao gênero Bacillus, que apresentou domínio.

O sucesso da capacidade das bactérias em degradar os fármacos testados possibilita inferir sobre a capacidade desses organismos em utilizar os compostos estudados como fonte de carbono no seu metabolismo. O uso de linhagens específicas de microrganismos capazes de metabolizar eficientemente esses fármacos pode vir a representar uma proposta para a ativação biológica de leitos de filtros de carvão na busca por desenvolver uma configuração de sistema que contribua para o aumento da eficiência e redução do custo do tratamento de água na remoção desses compostos.

O uso de filtros biológicos de carvão pode representar uma técnica promissora para a remoção de fármacos e outros compostos recalcitrantes presentes nos mananciais de abastecimento público.

\section{REFERÊNCIAS}

AKTAS, Ö. \& ÇEÇEN, F. (2007) Bioregeneration of activated carbon: a review. International Biodeterioration \& Biodegradation, v. 59, n. 4, p. 257-272.

BAI, Y.H.; SUN, Q.; ZHAO, C.; WEN, D.; TANG, X. (2009). Aerobic degradation of pyridine by a new bacterial strain, Shinella zoogloeoides BCO26. Journal of Industrial Microbiology \& Biotechnology, v. 36, n. 11, p. 1391-1400.

BASSO, E.R. \& CARVALHO, S.L. (2007) Avaliação da qualidade da água em duas represas e uma lagoa no município de llha Solteira (SP). Holos Environment, v. 7, n. 1, p. 16-20.

BLAU, L.; MENEGON, R.F.; CHIN-CHUNG, M. (2006) Pró-fármaco ativado por enzima, uma estratégia promissora na quimioterapia. Química Nova, v. 29, n. 6, p. 1307-1317.

BOURNE, D.G.; BLAKELEY, R.L.; RIDDLES, P.; JONES, G.J. (2006) Biodegradation of the cyanobacterial toxin microcystin LR in natural water and biologically active slow sand filters. Water Research, v. 40, N. 6, p. 1294-1302.
BRADY, R.D. (1997) Activated carbon processes. In: American Water Works Association - AWWA; American Society Of Civil Engineers ASCE. Water treatment plant design. New York: McGraw-Hill. p. 377-416.

BRUNAUER, S.; EMMETT, P.H.; TELLER, E. (1938) Adsorption of gases in multimolecular layers. Journal of the American Chemical Society, v. 60, n. 2, p. 309-319.

BUNDY, M.M.; DOUCETTE, W.J.; MCNEIL, L.; ERICSON, J.F. (2OO7) Removal of pharmaceuticals and related compounds by a bench-scale drinking water treatment system. Journal of Water Supply, Research and Technology - AQUA, v. 56, n. 2, p. 105-115.

CETESB-COMPANHIAESTADUALDETECNOLOGIA DESANEAMENTO BÁSICO (2004). Relatório da qualidade das águas interiores do Estado de São Paulo. São Paulo: CETESB.

CHAPMAN, P.M. (2006) Emergent substances: emerging problems? Environmental Toxicology and Chemistry, v. 25, n. 6, p. 1445-1447. 
CHUA, H.; YAP, M.G.S.; NG, W.J. (1996) Bacterial populations and their roles in a pharmaceutical-waste anaerobic filter. Water Research, v. 30, n. 12 , p. $3007-3016$

CORCORAN, E.; NELLEMANN, C; BAKER, E.; BOS, R.; OSBORN, D.; SAVELLI, H. (2010) Sick Water? The central role of wastewater management in sustainable development. A Rapid Response Assessment. Programa das Nações Unidas pelo Meio Ambiente PNUMA, UN-HABITAT, GRID-Arendal.

DANTAS, G.; SOMMER, M.O.; OLUWASEGUN, R.D.; CHURCH, G.M. (2OO8) Bacteria subsisting on antibiotics. Science, v. 320, n. 5872, p. 100-103.

DAUGHTON, C.G. (2001). Pharmaceuticals in the environment: overarching issues and overview. In: DOUGHTON, C.G \& JONESLEPP, T.L. (Eds.) Pharmaceuticals and personal care products in the environment: scientific and regulatory issues. Washington: American Chemical Society. p. 2-38. (Symposium Series, 791).

DI BERNARDO, L.; BRANDÃO, C.C.S.; HELLER, L. (1999) Tratamento de águas de abastecimento por filtração em múltiplas etapas. Rio de Janeiro: ABES. $114 \mathrm{p}$.

EWING, B. \& GREEN, P. (1998). Base-calling of automated sequencer traces using Phred II. Error probabilities. Genome Research, v. 8, n. 3, p. 186-194.

EWING, B.; HILLIER, L.; WENDL, M.C.; GREEN, P. (1998). Base-calling of automated sequencer traces using Phred I. Accuracy assessment. Genome Research, v. 8, n. 3, p. 175-185.

FENT, K.; WESTON, A.A.; CAMINADA, D. (2006) Ecotoxicology of human pharmaceuticals. Aquatic Toxicology, v. 76, n. 2, p. 122-159.

GHISELLI, G. (2006) Avaliação da qualidade das águas destinadas ao abastecimento público na região de Campinas: ocorrência e determinação dos interferentes endócrinos (IE) e produtos farmacêuticos e de higiene pessoal (PFHP). Tese (Doutorado em Química Analítica) - Universidade Estadual de Campinas, Campinas.

GILLES, C.H.; MACEWAN, T.H.; NAKHWA, S.N.; SMITH, D. (1960) A system of classification of solution adsorption isotherms, and its use in diagnosis of adsorption mechanisms and measurement of specific surface areas of solids. Journal of the Chemical Society, v. 2, p. 3973-3993.

HO, L.S.W. (2004) The removal of cyanobacterial metabolites from drinking water using ozone and granular activated carbon. Thesis (Ph.D.) - University of South Australia, Adelaide, Australia.

HUSMARK, U. \& RÖNNER, U. (1990) Forces involved in adhesion of Bacillus cereus spores to solid surfaces under different environmental conditions. Journal of Applied Microbiology, v. 69, n. 4, p. 557-562.

IWAKI, H. \& HASEGAWA, Y. (2007) Degradation of 2-nitrobenzoate by Burkholderia terrae strain KU-15. Bioscience, Biotechnology and Biochemistry, v. 71, n. 1, p. 145-151.

JONES, O.A.; LESTER J.N.; VOULVOULIS N. (2005) Pharmaceuticals: a threat to drinking water? Trends in Biotechnology, v. 23, n. 4, p. 163-167.

KHAN, S.A.; HAMAYUN, M.; AHMED, S. (2006) Degradation of 4-aminophenol by newly isolated Pseudomonas sp. strain ST-4. Enzyme and Microbial Technology, v. 38, n. 1-2, p. 10-13.
LEMES, G.A.; KERSANACH, R.; PINTO, L.S.; DELLAGOSTIN, O.A.; YUNES, J.S.; MATTHIENSEN, A. (2008) Biodegradation of microcystin by aquatic Burkholderia sp. from a South Brazilian coastal lagoon. Ecotoxicology and Environmental Safety, v. 69, n. 3, p. 358-365.

LÓPEZ, L.; POZO, C.; RODELAS, B.; CALVO, C. JUÁREZ, B.; MARTÍNEZTOLEDO, M.V.; GONZÁLEZ-LÓPEZ, J. (2005) Identification of bacteria isolated from an oligotrophic lake with pesticide removal capacities. Ecotoxicology, v. 14, n. 3, p. 299-312.

MAIDAK, B.L. (2010) Michigan State University. Ribosomal Database Project II. Disponível em: <http://rdp.cme.msu.edu/>. Acesso em: 10 maio 2010.

MINILLO, A.; ISIQUE, W.D.; ALVES-PRADO, H.F.; TANGERINO, E.P. (2OO9) Biodegradação de fármacos na água por microrganismos associados em filtros biológicos de carvão. Revista DAE, v. 179, p. 42-49.

MURDOCH, R.W. \& HAY, A.G. (2005) Formation of catechols via removal of acid side chains from ibuprofen and related aromatic acids. Applied and Environmental Microbiology, v. 71, n. 10, p. 6121-6125.

NEBOT, C; GIBB, S.W.; BOYD, K.G. (2007) Quantification of human pharmaceuticals in water samples by high performance liquid tography-tandem mass spectrometry. Analytica Chimica Acta, v. 598, n. 1, p. 87-94

PAIXÃO, D.A.A. (2009) Prospecção gênica e diversidade bacteriana de um consórcio degradador de óleo diesel. Dissertação (Mestrado em Microbiologia) - Faculdade de Ciências Agrárias e Veterinárias, Universidade Estadual Paulista "Júlio de Mesquita Filho", Jaboticabal.

PARK, H.D.; SASAKI, Y.; MARUYAMA, T.; YANAGISAWA, E.; HIRAISHI, A.; KATO, K. (2001) Degradation of the cyanobacterial hepatotoxin microcystin by a new bacterium isolated from a hypertrophic lake. Environmental Toxicology, v. 16, n. 4, p. 337-343.

PEREIRA, M.O. (2001). Comparação da eficiência de dois biocidas (carbamato e glutaraldeído) em sistemas de biofilme. Tese (Doutorado em Engenharia Química e Biológica) - Universidade do Minho, Braga, Portugal.

PETROVIC, M.; HERNANDO, M.D.; DIAS-CRUZ, M.S.; BARCELÓ, D. (2005) Liquid chromatography-tandem mass spectrometry for the analysis of pharmaceutical residues in environmental samples: a review. Journal of Chromatography A, v. 1067, n. 1/2, p.1-14.

REIS FILHO, R.W.; BARREIRO, J.C.; VIEIRA, E.M.; CASS, Q.B. (2007) Fármacos, ETEs e corpos hídricos. Revista Ambiente \& Água, v. 2, n. 3, p. 54-61.

RIBEIRO, F.A.L. \& FERREIRA, M.M.C. (2008) Planilha de validação: uma nova ferramenta para estimar figuras de mérito na validação de métodos analíticos univariados. Química Nova, v. 31, n. 1, p. 164-171.

SAYERS, E.W. (2010) U.S. Department of Health And Human Services (Org.). National Center for Biotechnology Information (NCBI). Disponível em: <http://blast.ncbi.nlm.nih.gov/Blast.cgi >. Acesso em: 10 jun 2010.

SEREDYNSKA-SOBECKA, B.; TOMASZEWSKA, M.; JANUS, M.; MORAWSKI, A.W. (2006). Biological activation of carbon filters. Water Research, v. 40, n. 2, p. 355-363. 
SERVAIS, P.; BILLEN, G.; BOUILLOT, P.; BENEZET, M. (1992). A pilot study of biological GAC filtration in drinking-water treatment. Journal of Water Supply, Research and Technology - AQUA, v. 41, n. 3, p.163-168.

SIMPSON, D.R. (2008) Biofilm processes in biologically active carbon water purification. Water Research, v. 42, n. 12, p. 2839-2848.

SMITH, G.B.; DEZENY, G.C.; DOUGLAS, A.W. (1990) Stability and kinetics of degradation of imipenem in aqueous solution. Journal of Pharmaceutical Sciences, v. 79, n. 8, p. 732-740.

TAVARES, B.M. (2008) Utilização de colunas verticais de filtração em manta e areia como pré-tratamento de filtro lento. 2008. Dissertação (Mestrado) - Faculdade de Engenharia de Ilha Solteira, Universidade Estadual Paulista "Júlio de Mesquita Filho", Ilha Solteira.

TORSVIK, V. \& ØVREÅS, L. (2002) Microbial diversity and function in soil: from genes to ecosystems. Current Opinion in Microbiology, v. 5, n. 3, p. 240-245.
TORTORA, G.J.; FUNKE, B.R.; CASE, C.L. (2003) Microbiologia. São Paulo: Artmed.

WANG, H.; HO, L.; LEWIS, D.M.; BROOKES, J.D.; NEWCOMBE, G. (2007) Discriminating and assessing adsorption and biodegradation removal mechanisms during granular activated carbon filtration of microcystin toxins. Water Research, v. 41, n. 18, p. $4262-4270$.

WATANABE, K. (2001) Microorganisms relevant to bioremediation. Current Opinion in Biotechnology, v. 12, n. 3, p. 237-241.

WEBB, S.; TERNES, T.; GILBERT, M.; OLEJNICZAK, K. (2003) Indirect human exposure to pharmaceuticals via drinking water. Toxicology Letters, v. 142, n. 3, p. 157-167.

ZWIENER, C. \& FRIMMEL F.H. (2000) Oxidative treatment of pharmaceuticals in water. Water Research, v. 34, n. 6, p. 1881-1885. 